\title{
Social Identity, Self-Categorization, and the Communication of Group Norms
}

\author{
Michael A. Hogg ${ }^{1}$ \& Scott A. Reid ${ }^{2}$ \\ 1 School of Psychology, University of Queensland, Brisbane, QLD 4072, Australia \\ 2 Department of Communication, University of California, Santa Barbara, CA 93106-4020
}

\begin{abstract}
We articulate the role of norms within the social identity perspective as a basis for theorizing a number of manifestly communicative phenomena. We describe how group norms are cognitively represented as context-dependent prototypes that capture the distinctive properties of groups. The same process that governs the psychological salience of different prototypes, and thus generates group normative behavior, can be used to understand the formation, perception, and diffusion of norms, and also how some group members, for example, leaders, have more normative influence than others. We illustrate this process across a number of phenomena and make suggestions for future interfaces between the social identity perspective and communication research. We believe that the social identity approach represents a truly integrative force for the communication discipline.
\end{abstract}

doi:10.1111/j.1468-2885.2006.00003.x

There is much made, particularly in Western societies, of individuality—how people are uniquely different from one another. However, if you observe a group of teens, or some friends at a restaurant, or a large crowd at a soccer match, you will also be struck at how similar people are to one another in dress and behavior. Groups and situations seem somehow to submerge uniqueness in a sea of commonality, and the same person behaves differently as he or she moves from situation to situation and group to group. Indeed, groups and situations have their own behavioral attributes that regulate the behavior of people in the situation or belonging to the group. These attributes are norms - they sharply map the contours of different situations and different groups, and pattern social experience not into different unique individuals but into different unique groups and situations.

In this article, we focus on group norms, defined as regularities in attitudes and behavior that characterize a social group and differentiate it from other social groups. In this way we tie norms to human groups rather than, for example, simple aggregates of people. We adopt the social identity perspective on groups and self-conception to describe the social cognitive and social interactive processes that influence, are

Corresponding author: Michael A. Hogg; e-mail: mike@psy.uq.edu.au or Scott A. Reid; e-mail: scottreid@comm.ucsb.edu. 
influenced by, and are associated with group norms. Thus, we focus on the causal relationship between group norms and individual group members' representation of such norms - causally linking what Lapinski and Rimal (2005) (also see Arrow \& Burns, 2004) and others refer to as collective norms and perceived norms.

The social identity perspective does a good job, we feel, of theorizing the social cognitive and self-conceptual functions and dimensions of group norms. It also points quite explicitly at the role of social interaction and communication in normative phenomena. Norms are shared patterns of thought, feeling, and behavior, and in groups, what people do and say communicates information about norms and is itself configured by norms and by normative concerns (e.g., Hogg \& Tindale, 2005). This communication can be indirect-people infer norms from what is said and donebut it can also be direct: people intentionally talk about, or nonverbally signal, what is and what is not normative of the group. Although communication scholars quite explicitly focus on the communicative dimension of norms (e.g., Arrow \& Burns, 2004; Bendor \& Swistak, 2001; Kincaid, 2004; Lapinski \& Rimal, 2005; Rimal \& Real, 2003), this critical communicative dimension of norms has yet to receive sustained theoretical and empirical attention within and from the social identity analysis of norms.

The aim of this article is to describe what the contemporary social identity perspective has to say about group norms and normative behavior, and the role of communication in social identity-contingent normative phenomena. In order to do this, we first give a brief integrative overview of the contemporary social identity approach in social psychology_focusing on those aspects of theory that have most relevance to normative phenomena. We then critically assess what the social identity perspective has to say about the role of communication in those areas where it has addressed communication. Under the three broad headings of "perception of norms," "diffusion of norms within and between groups," and "differential influence on group norms," we cover research and theory on normative attitudes and behavior, third-person perception, pluralistic ignorance, conformity and polarization, group decision making, leadership, deviance, and schisms.

We argue that the social identity perspective provides a sound account of group norms, primarily at a social cognitive level of analysis that focuses on how individuals represent norms, and show that although there is significant scope for conceptual focus on the role of communication, this potential has not yet been fully exploited. We believe that the contemporary social identity approach has rich potential to serve as an integrative force for a communication perspective on group norms and that this is fertile ground for future research.

\section{The social identity perspective}

The social identity perspective is a social psychological analysis of group processes, intergroup relations, and the self-concept (Tajfel \& Turner, 1979; Turner, Hogg, Oakes, Reicher, \& Wetherell, 1987; also see Hogg \& Abrams, 1988, and for contemporary integrative statements, see Hogg, 2003, 2005b, 2006). Its core tenet is that people 
derive a part of their self-concept from the social groups and categories they belong to--their social identity, originally defined as “... the individual's knowledge that he belongs to certain social groups together with some emotional and value significance to him of this group membership" (Tajfel, 1972, p. 292). Predicated on a systematic critique of individualistic conceptions of self and group processes (e.g., Turner \& Oakes, 1986), the conceptual focus is on the collective self-self defined in group terms and connected to fellow group members (cf. Brewer \& Gardner, 1996; Markus \& Kitayama, 1991; Oyserman, Coon, \& Kemmelmeier, 2002). Social cognitive processes associated with social identity produce group and intergroup behaviors.

The social identity perspective embraces a number of integrated sub-theories, among which the most significant are social identity theory (Tajfel \& Turner, 1979), more accurately characterized as "the social identity theory of intergroup behavior" (Turner et al., 1987, p. 42), and self-categorization theory (Turner et al., 1987), more accurately characterized as "the social identity theory of the group" (Turner et al., 1987, p. 42).

Social identity theory focuses on prejudice, discrimination, and conditions that promote different types of intergroup behavior-for example, conflict, cooperation, social change, and social stasis. An emphasis is placed on intergroup competition over status and prestige, and the motivational role of self-enhancement through positive social identity. Giles and colleagues adapted and extended social identity theory in their work on ethnolinguistic identity theory (Giles \& Johnson, 1981, 1987) and communication accommodation theory (see Giles \& Coupland, 1991) developments that took place and continue within the field of communication.

Self-categorization theory focuses on the basic social cognitive processes, primarily social categorization, that cause people to identify with groups, construe themselves and others in group terms, and manifest group behaviors. It has been central in the development of other conceptual components of the social identity approach, such as those dealing with leadership, social influence, group polarization, social attraction, and group cohesiveness. However, because self-categorization theory focuses on cognitive processes, the contemporary complexion of the social identity approach (e.g., see Hogg, 2003, 2005b, 2006) is more heavily influenced by cognitive constructs than was the original social identity theory of intergroup relations. The contemporary social identity approach rarely has much to say explicitly about communication issues and is ripe for development in this direction (see Reid, Giles, \& Harwood, 2005).

\section{Social categorization, self-conception, and norms}

Social categorization lies at the core of the social identity approach. Tajfel's original formulation was framed by his work on social categorization and perceptual accentuation (e.g., Tajfel, 1959), social categorization and prejudice (Tajfel, 1969), and social categorization and discrimination (e.g., Tajfel, Billig, Bundy, \& Flament, 1971); social categorization is central to the more recent self-categorization theory (Turner et al., 1987). 
To foreshadow our social identity analysis of norms, norms are shared cognitive representations that, within a particular context, characterize the behavior of members of relevant out-groups and describe and prescribe the behavior of in-group members including ourselves (cf. Turner, 1991). Although this provides, we believe, a cogent social cognitive analysis of norms, social interactive and communicative aspects have yet to be properly specified.

\section{Categories and prototypes}

Individuals cognitively represent social categories as prototypes. These are fuzzy sets, not checklists, of attributes (e.g., attitudes and behaviors) that define one group and distinguish it from other groups. These category representations capture similarities among people within the same group and differences between groups. In other words, they accentuate intragroup similarities (assimilation) and intergroup differences (contrast) (cf. Tajfel, 1959) and thus transform a bewilderingly diverse social stimulus domain into a smaller set of distinct and clearly circumscribed categories. Group prototypes submerge variability and diversity in a single representation that characterizes an entire human group.

Technically, prototypes obey the metacontrast principle - they maximize the ratio of intergroup differences to intragroup differences. By so doing, they also enhance perceived entitativity - the property of a group that makes it appear to be a coherent and distinct entity that is homogeneous and well structured, has clear boundaries, and whose members share a common fate (Campbell, 1958; Hamilton \& Sherman, 1996).

A critical implication of this analysis of group prototypes is that group representations are inextricable from intergroup comparisons-they are based on comparisons within and between groups. Specifically, we configure our intragroup representations so that they accentuate differences between the group and the relevant out-groups. For example, our representation of vegetarians will be different if we are comparing them to vegans or to carnivores. In this sense, group prototypes are context dependent rather than fixed-they vary from context to context as a function of the social comparative frame (situation, goals, and people physically or cognitively present). Typically, variability may be relatively modest due to the anchoring effect of enduring and highly accessible representations of important groups we belong to or know about, but it may be more dramatic in new groups or groups that we know less about.

\section{Social categorization and depersonalization}

When we categorize people, we reconfigure our representation of them to conform to the context-dependent prototype of the category-once categorized, people are viewed through the lens of the relevant group prototype and are represented in terms of how well they embody the prototype. In this way, social categorization depersonalizes our perception of people - they are not viewed as unique individuals but as embodiments of the attributes of their group. Since group prototypes specify how people feel, perceive, think, and behave, social categorization generates stereotypical 
expectations and encourages stereotype-consistent interpretation of ambiguous behaviors. This effect is more marked as a function of the degree to which you feel the person is group prototypical. For example, in the United States, a British accent is likely to generate stereotypic perceptions and expectations (e.g., Scherer \& Giles, 1979), which will be more pronounced as a function of how British the accent is.

Because social categorization almost always involves self or is in reference to self, we not only categorize others but also categorize self. This is the key insight of selfcategorization theory (Turner et al., 1987). Self-categorization has exactly the same effect as categorization of others-it depersonalizes self-perception in terms of the in-group prototype as described above for the categorization of others. However, self-categorization has additional effects; it not only transforms self-conception and generates a feeling of belonging and group identification, but also transforms how we actually feel and behave to conform to the group prototype. Self-categorization causes our thoughts, feelings, perceptions, and behavior to conform to our prototype of the in-group.

\section{From prototypes to group norms}

It is only a short step from prototypes to group norms. Although we can of course have idiosyncratic group prototypes, such prototypes are unlikely to persist if no one agrees with us. For example, if only I believe that my group is fun loving and jolly, my stereotypic expectations and actual social interactions will continually be thwarted by the stark reality that my group is dour and miserable-furthermore, my idiosyncratic views may marginalize me so that my fellow group members will think me odd and not really a group member at all. On the contrary, group prototypes are grounded in consensual views that constitute a social reality that is reinforced over and over again (cf. Moscovici, 1976). Prototypes tend to be shared-people in one group in the same context share their prototype of the in-group and relevant outgroup(s). In this sense, group prototypes are group norms (Turner, 1991).

Tajfel (1981) made almost the same point about out-group stereotypesreminding us that social stereotypes are shared beliefs held by one group about another group. Again focusing primarily on out-group stereotypes, Oakes, Haslam, and Turner (1993) argue that such stereotypes are not idiosyncratic and inaccurate beliefs but accurate beliefs precisely because they reflect a shared social reality.

From a social identity perspective, group prototypes describe individual cognitive representations of group norms. And, importantly, the process of depersonalization based on self-categorization, described above, produces conformity to shared in-group prototypes and thus produces in-group normative behavior. The social identity theory-based distinction between group prototypes and group norms helps specify generative processes underlying similar distinctions such as that between perceived norms and collective norms (e.g., Lapinski \& Rimal, 2005). So, for example, our discussion of social identity and prototypes specifies very clearly the social cognitive processes involved in people's perception of group norms and the social 
processes involved in translating individual prototypes into shared prototypeswhere shared prototypes are group norms.

\section{Social identity salience}

For a social categorization to produce normative behavior, the categorization must be psychologically salient as the basis for perception and self-conception-people must psychologically identify with their in-group in that context. The principle governing social identity salience, developed and elaborated by Oakes (1987) from work by Bruner (1957), rests on the two notions of accessibility and fit.

People draw on readily accessible social categorizations-ones that are valued, important, and frequently employ aspects of the self-concept (they are chronically accessible in memory)_because they are self-evident and perceptually salient in the immediate situation (they are situationally accessible). For example, gender and race are social categorizations that are often both chronically and situationally accessible (e.g., Mackie, Hamilton, Susskind, \& Rosselli, 1996).

People use accessible categories to make sense of their social context. They investigate how well the categorization accounts for similarities and differences among people (called structural or comparative fit) and how well the prototypical properties of the categorization account for why people behave as they do (called normative fit). If the fit of the categorization is poor (e.g., similarities and differences do not correspond to people's gender or race, and people do not behave in genderor race-stereotypical ways), people cycle through other accessible categorizations (e.g., political orientation, religion, profession) until an optimal level of fit is obtained. This process is not entirely automatic. People are motivated to make categorizations that favor the in-group fit and may go to some lengths to do this. Salience is not only a cognitive perceptual process but also a social process in which people may compete or "negotiate" over category salience.

The categorization that has optimal fit becomes psychologically salient in that context as the basis of self-categorization, group identification, and prototype-based depersonalization. It accentuates in-group similarities and intergroup differences, enhances perceived entitativity, and underpins context-relevant group and intergroup behaviors.

\section{Descriptive and prescriptive group norms}

The social identity analysis of norms may have implications for the distinction between descriptive and prescriptive/injunctive group norms (e.g., Cialdini, Kallgren, \& Reno, 1991). Communication scholars largely view injunctive norms as having their prescriptive force because there are perceived social sanctions for their violation (see Bendor \& Swistak, 2001; Lapinski \& Rimal, 2005; Rimal \& Real, 2003)—people comply with such norms because other people, "out there," might disapprove if they do not. In contrast, social identity scholars attribute the prescriptive force of group norms to their internalized self-definitional function (e.g., Abrams \& Hogg, 1990)a perspective resting on the social identity critique of traditional dual-process models 
of social influence (see below). From a social identity perspective, in-group prototypes not only describe behavior but also prescribe it-telling us how we ought to behave as group members. In this sense, norms that define an in-group that we identify with may have significant potential to actually influence our behavior (Terry \& Hogg, 1996; see below).

The prescriptive force of the prototype is likely to be stronger when the in-group is important to who we are, when we identify strongly or have a strong desire to be accepted as (more central) members of the group, and when the group's value, definition, or very existence is under threat (cf. Christensen, Rothgerber, Wood, \& Matz, 2004). In-group prototypes have prescriptive potential because they define and evaluate who we are-they are closely tied to self-conception.

However, out-group norms also affect behavior. From a social identity perspective, out-group norms can have a significant impact on how we construct in-group norms, particularly in the absence of clear in-group normative information. Specifically, we construct an in-group norm that is polarized away from the out-group and then conform to our in-group norm via self-categorization-based depersonalization, thus producing group polarization (discussed below, but see Turner, Wetherell, \& Hogg, 1989) or an apparent counterconformity to wider societal out-group norms.

\section{Social interaction, social influence, and communication}

As described above, group prototypes are tied to social categories and identities, and are anchored in social consensus that makes them normative. This renders them relatively adaptive perceptions of the social world and our place within it that reduce uncertainty and regulate social perception and social interaction (e.g., Hogg, 2000). We construct and modify our normative beliefs through information from other people-people we interact with or who influence us more indirectly through mass media.

The social identity theory of influence in groups is called referent informational influence theory (e.g., Turner, 1982; also see Abrams \& Hogg, 1990; Hogg \& Turner, 1987; Turner, 1991; Turner \& Oakes, 1989). The categorization/depersonalization processes described above explain the social cognitive basis of normative behavior. However, referent informational influence theory makes additional claims. The first is that conformity and normative behavior represent internal cognitive change in a given context rather than superficial behavioral compliance or obedience-this is because in-group prototypes are internal, self-defining cognitive representations (they are "in here") not external constraints ("out there"). This contrasts with, and is predicated on a critique of traditional dual-process models of influence (e.g., Deutsch \& Gerard, 1955) that attribute a significant portion of group influence to social sanction-based compliance.

The second claim is that because in-group prototypes are self-defining, people in salient groups pay close attention to the prototype, to information that delineates the prototype, and to people who provide information about the prototype (Hogg, 2005a; also see Reicher's, 1984, 2001, analysis of crowd behavior). People also know, 
and strive to know, with some precision how well they themselves match the prototype, how well others match the prototype, and how prototypical others think one is (e.g., Haslam, Oakes, McGarty, Turner, \& Onorato, 1995). In essence, then, social influence (true persuasion) is described by the internalization of a contextually salient in-group norm, which serves as a basis for self-definition, and thus attitude and behavior regulation.

Communication plays a key role in social influence and consensual grounding of norms (e.g., Kincaid, 2004; Lapinski \& Rimal, 2005)—indeed, it is difficult to imagine how else influence occurs and how else information about norms, identity, and prototypicality is acquired, validated, or changed (e.g., Noels, Giles, \& Le Poire, 2003). For example, stories embedded in narrative and discourse manage bonds among group members (Bochner, Ellis, \& Tillman-Healy, 2000), construct representations of social categories (Edwards, 1997), and such representations of group (and situational) norms influence what people actually talk about (Côté \& Clément, 1994). People also tend to use more abstract language to describe behaviors that are consistent with normative expectations and more concrete language to describe behaviors that are inconsistent with normative expectations (Maass, 1999; Wigboldus, Semin, \& Spears, 2000). Above all, common category membership facilitates intersubjectivity and thus provides a framework for meaning-making that allows people to construct a shared representation of their social world, a shared world view, that is normative for their group (Clark \& Brennan, 1991; Higgins, 1992; Thompson \& Fine, 1999).

Yet, this communication dimension is hardly explored at all by social identity researchers. Within groups, information about the prototype and who is most prototypical can be gleaned by simply observing how people behave-what they do, how they dress, what they say, and so forth. Such information can also be intentionally communicated nonverbally through gestures and expressions (e.g., Burgoon, Buller, \& Woodall, 1996) or verbally by actually talking about what is and what is not normative of the group. People can ask direct questions to find out what is normative, or they can engage more indirectly in discussion designed to elicit attitudinal positions that are normative or not (cf. Lapinski \& Rimal, 2005). Furthermore, members can manage their own prototypicality verbally and nonverbally-they can "talk up" or "talk down" their prototypicality directly or by reference to other members' prototypicality. They can, particularly verbally, offer competing interpretations or constructions of the group prototype and of what their social identity means. This entire process is highly dynamic and is prey to motivated perception, subjective interpretation, and inaccurate reading of cues.

We would argue that when group membership is salient, a significant portion of what is communicated within an interactive group or among members of larger social categories is directly or indirectly about or contextualized by group norms (Hogg \& Tindale, 2005). In some group contexts, for example, when member socialization is important, norm-related communication may be more prominent than in other contexts (cf. Levine \& Moreland, 1994; Tuckman, 1965). 
For the remainder of this article, we discuss group norms and normative phenomena in the context of social identity and communication processes, in order to show some support for the social identity analysis of group norms and to identify communication lacunae in social identity literature and normative lacunae in communication research.

\section{Perception of norms}

Inferring normative attitudes from what people say

In small interactive groups, people tend to infer their group's norms most directly from what people say and do. For example, we might infer the normative attitudes of our group from the expressed attitudes or actual behaviors of fellow group members. However, people do not always say what they really think or behave in ways that reflect their underlying attitudes (Ajzen \& Fishbein, 1980; also see Fazio \& Olson, 2003); therefore, inferring underlying attitudes from expressed attitudes or overt behavior may be unreliable.

Of particular relevance to our social identity analysis is research by Terry and her colleagues, which argues that people are more likely to express their underlying attitudes in behavior if they identify strongly with a group for which the attitude (and associated behavior) is normative (e.g., Terry \& Hogg, 1996, 2001). The relationship between attitudes and behavior is more reliable in groups that people identify strongly with. An implication of this, which has not yet been explored conceptually or empirically, is that people are better able to infer attitudinal norms from what members say, their expressed attitudes, if the group is highly salient and members identify strongly. However, there may be an intriguing twist to this. If people believe that attitudes and behavior are more closely associated in salient groups, they may also believe that they are making more reliable inferences about attitudinal norms from what people say. There is now an opportunity for people to intentionally manipulate, through what they say and do, the group's perception of what is normative. Those people who are good at this can be considered "entrepreneurs of prototypicality," which may be a skill that is closely associated with effective leadership — this is an argument that we develop below in our discussion of social identity and leadership.

Normative inference in the context of mass media

There is a range of media perception phenomena that are amenable to a social identity analysis of norms. Among others, third-person perceptions and pluralistic ignorance are traditionally framed as perceptual errors and share a more than passing resemblance that invites a common explanation. The current state of theory in communication seems limited in achieving this goal. However, some recent data suggest that both can be explained by a common social identity process associated with perceptions of salient self-categories and attendant group norms (Reid, Byrne, Brundidge, Shoham, \& Marlow, 2005). 
The third-person effect (Davison, 1983) is a perception that one is less influenced by the media than other people and a consequent attitude that favors media restriction. Research confirms the existence of third-person perceptions (e.g., Perloff, 1993), but there is relatively little work that explains them. There is also evidence for a correlation between third-person perceptions and media restrictions-this part of the phenomenon is less well researched, but there is some evidence that selfcategorization theory may help explain it (Reid, Byrne, et al., 2005; also see Duck, Hogg, \& Terry, 1999). Here we focus on the perceptual component.

Reid and Hogg (2005) provide evidence that self-categorization explains both first- (self more influenced than others) and third-person (other influenced more than self) perceptions. Specifically, people judge the extent to which the particular media are normative of the group to which the other person, and self, belongs, and this drives the perception of relative influence of the media. When the other person is an out-group member, media that are normative of the in-group produce first-person perceptions (I am more influenced than them) and media that are out-group normative produce third-person perceptions (they are more influenced than me).

By highlighting the salience of student identity and crossing comparison target (e.g., "trailer trash" vs. Wall Street bankers) with media (e.g., National Enquirer vs. the Wall Street Journal), Reid and Hogg found third-person perceptions when the out-group target fitted the media (i.e., trailer trash and the Enquirer, the banker and the Journal), but first-person perceptions when self fit the media more strongly than the out-group target (i.e., self vs. trailer trash on the Journal, and self vs. the banker on the Enquirer). Thus, the same media can produce strong first- or third-person perceptions depending upon the extent to which the media are perceived to be normative of the in-group or out-group, respectively.

Further, and importantly, the size of these effects was moderated by the relative prototypicality of the perceiver. The more prototypically similar participants judged themselves to the comparison target, the smaller the third-person perception, but only when the media were judged to be normative for that comparison target. For example, the more similar students judged themselves to trailer trash, the less the third-person perception judgment for the National Enquirer, but not for the Wall Street Journal or Friends. In other words, people use in-group normative media to differentiate self from an out-group, and this process governs the size of the resulting third-person perception.

Pluralistic ignorance (e.g., Prentice \& Miller, 1996) occurs where people privately reject an in-group norm but erroneously believe that most others in the group accept the norm. A frequently cited demonstration of this is provided by Prentice and Miller (1993). In several studies, Princeton students were asked, "how comfortable do you feel with the alcohol drinking habits of students at Princeton," and "how comfortable does the average Princeton undergraduate feel ...” (1993, p. 245). The finding that people believe others are more comfortable than themselves is taken by Prentice and Miller as "widespread evidence of pluralistic ignorance" (1993, p. 243). Thus, 
pluralistic ignorance is considered to be a perceptual paradox-nobody in the group says they engage in the behavior (so in reality it is not the norm); yet, everybody in the group assumes everyone else does engage in the behavior (so it is the group norm). Prentice and Miller assume, but do not actually measure, that in reality, everyone in the group does engage in the behavior.

Reid, Cropley, and Hogg (2005) question the assumption that lack of comfort with the group norm is accompanied by norm-consistent behavior. From the social identity perspective, it is assumed that attitudes and behaviors will be highly consistent so long as social identity is salient (see above). Further, it is assumed that there will be variation within groups in the degree to which people conform to group norms. More prototypical people will report more normative behavior; less prototypical people, less normative behavior. It is therefore possible that behavioral consistency between attitudes and behavior can be found if we take the prototypicality of the social perceiver into account.

Reid, Cropley, et al. (2005) conducted a survey of student drinking perceptions at University of California, Santa Barbara (UCSB). Consistent with predictions, on average, students estimated that they were less comfortable with drinking than the average undergraduate (replicating Prentice and Miller's finding), but this main effect was moderated by prototypicality. Those students who considered themselves highly prototypical UCSB students did not show pluralistic ignorance, whereas students who considered themselves less prototypical showed an amplified pluralistic ignorance effect. What is more, these same effects were replicated on items that measured how typical it is for self and other undergraduates to drink and estimates of standard drinks consumed per week - in other words, we did not find substantiation for the assumption that all group members engage in the group norm, despite being uncomfortable with it. In fact, consistent with self-categorization theory, we found that prototypicality predicted self-reported drinking and that this relationship was mediated by personal comfort with drinking. Thus, our data provide no evidence for pluralistic ignorancepeople's attitudes and behaviors are consistent and are based upon differentiation within the group around the prototypical group position.

\section{Diffusion of norms within and between groups}

\section{Conformity and group polarization}

People in groups use other members' behavior as information to construct a group norm. The classic studies of norm formation are of course Sherif's autokinetic studies (e.g., Sherif, 1935, 1936), in which participants in small groups adjusted their estimation of movement of a light source so that it more tightly converged on the average of the range of estimations made by all members. A true norm had arisenthe norm persisted even when all original members of the group had left and the group had entirely new members (MacNeil \& Sherif, 1976).

Traditionally, norms are conceptualized as reflecting the individual's use of others' behavior as information about the nature of reality or as reflecting behavioral 
compliance to gain social acceptance and avoid social censure (e.g., Deutsch \& Gerard, 1955)—normative behavior should therefore strengthen when people are unsure of their perceptions or when they are in the physical presence of people they wish to impress. From a social identity point of view, however, norms reflect a shared group prototype. Therefore, norm formation and normative behavior should strengthen and be more rapid and complete when people identify strongly with the group defined by the norm. This prediction has been confirmed in a Sherif-style autokinetic study by Abrams, Wetherell, Cochrane, Hogg, and Turner (1990).

Sherif's norm formation studies, along with most other studies of norms, assume that a group norm is the average in-group position. However, from a social identity point of view, as discussed earlier, norms do not have to be the average in-group position - we saw how prototypes, as individual representations of group norms, are formed from intra- and intergroup comparisons that obey the metacontrast principle and thus polarize norms to differentiate between groups. As the intergroup comparative context changes, the in-group norm changes to maintain intergroup differentiation.

This idea has been tested using variants of the group polarization paradigm (Moscovici \& Zavalloni, 1969; also see Isenberg, 1986) in which group discussion produces a final group position that is more extreme than the average of the initial members' positions in a direction displaced away from the out-group. A number of social identity studies have found that polarization is more extreme when members identify more strongly with the group (e.g., Abrams et al., 1990; Mackie, 1986; Mackie \& Cooper, 1984; Turner et al., 1989; also see Abrams \& Hogg, 1990; Turner \& Oakes, 1989). Little research has examined the communicative dimension of the group discussion process that produces a polarized norm. Reid and Ng (2000), however, show that people who use utterances that are prototypical of their group are more likely to get to speak than people whose utterances are less prototypical of their group. The polarization of the group norm is constituted in and reinforced by prototypical language.

\section{Group decision making}

Research on group polarization is part of a larger tradition of research into group decision making-resting on recognition that one common reason for people to be in small interactive groups is to make decisions and that group decision making involves communication, usually via talk, to establish a group position or norm. The challenge for groups is how to combine information to arrive at a group position, and here a key feature is that there is both shared and unshared information (e.g., Stasser \& Titus, 1985, 1987).

Because groups have a tendency to discuss shared rather than novel, unshared, information (Larson, Foster-Fishman, \& Keys, 1994), majority views and normconsistent decisions tend to win out. There is also evidence that group members who communicate shared information are viewed more favorably than are members who bring up unshared information (Wittenbaum, Hubbell, \& Zuckerman, 1999) 
and that shared information is considered more valid. There is also indirect evidence that over time, group discussion tends to strain out norm-inconsistent attitudes and narrow its scope to focus on norm-consistent information (e.g., Kashima, 2000). Indeed, as we shall see below, members who espouse nonnormative positions are often discredited as marginal members or deviants (e.g., Marques, Abrams, \& Serôdio, 2001). Direct criticism of group norms is more effective and more tolerated by the group if the critic is viewed by the group as an in-group, not out-group, member (Hornsey \& Imani, 2004).

Overall, group decision making is heavily impacted by group norms that define a common social identity-and presumably the process is amplified by increased cohesion and strong identification. One advantage of this is that communication will flow more smoothly and efficiently because it rests on a shared reality and world view (shared definitions of terms, implicit knowledge inferred, etc.). However, a diversity of opinions, viewpoints, and identities, which is associated with more bumpy communication, often produces better group decisions (e.g., Stasser, Stewart, \& Wittenbaum, 1995)—for example, it helps prevent groupthink (e.g., Postmes, Spears, \& Cihangir, 2001).

\section{Differential influence on group norms}

Groups are almost always internally differentiated so that some people have more influence than others over the life of the group and, in particular, on the configuration of group norms. Some positions within a group are more influential than others in determining what is normative or prototypical of group membership and what group membership means. The vehicle for this influence is verbal and nonverbal communication.

\section{Central members and leaders}

In most groups, the most influential person is the leader. An effective leader is able to transform individual action into group action by influencing others to embrace as their own and exert effort on behalf of, and in pursuit of, new group normative values, attitudes, goals, and behaviors. For the social identity theory of leadership (Hogg, 2001; Hogg \& van Knippenberg, 2003; van Knippenberg \& Hogg, 2003), the core idea is that as group membership becomes increasingly salient, members pay more attention to prototypicality and endorse prototypical leaders more strongly than nonprototypical leaders (for a recent empirical review, see van Knippenberg, van Knippenberg, De Cremer, \& Hogg, 2004).

Prototypical members or leaders are more influential for a number of social identity related reasons. (a) They embody the prototype and are therefore the focus of conformity within the group-follower behavior automatically conforms to their behavior. (b) They are liked by fellow members precisely because they embody the prototype-this allows them to gain compliance with their wishes and makes them appear to occupy a higher status position within the group. (c) They typically 
identify more strongly with the group than do others, and as such, they tend automatically to behave in more group-oriented and group-serving ways. (d) These behaviors benefit the group as a whole and generate trust in the leader not to harm the group-followers allow the leader to be innovative in taking the group in new directions. (e) Prototypical members are the focus of attention within the group because members feel they are the best source of information about the group norm-because they are figural against the background of the group, members are more likely to attribute their behavior (influence, status and popularity, group commitment, group orientedness, trustworthiness, innovativeness) to stable personality attributes that suit them to leadership (i.e., charisma).

Communication is central to prototype-based leadership. For example, in organizational contexts, effective leadership often rests on norm and identity management through talk (e.g., Fiol, 2002; Gardner, Paulsen, Gallois, Callan, \& Monaghan, 2001). Leaders need to manage their prototypicality - they need to communicate their own image of their prototypicality to their followers (e.g., Reid \& Ng, 2000), and one reason they are more effective at this is that they adopt a relatively powerful speech style (Reid \& Ng, 1999). They are effectively entrepreneurs of identity and experts in norm/ prototype management through verbal and nonverbal communication.

Leaders can talk up their own prototypicality and talk down aspects of their own behavior that are nonprototypical. They can target deviants or marginal members so as to highlight their own prototypicality or construct a prototype for the group that enhances their own prototypicality. They can secure their own leadership position by vilifying contenders for leadership and characterizing them as nonprototypical. They can identify as relevant comparison out-groups those that are most favorable to their own prototypicality, that is, they can manipulate the social comparative frame and thus the prototype and their own prototypicality. They can engage in a discourse that increases or diminishes in-group salience. If one is highly prototypical, raising salience provides the leadership benefits of high prototypicality; if one is not very prototypical, lowering salience protects one from the leadership pitfalls of low prototypicality.

Research by Reicher and Hopkins $(1996,2001)$ on political leaders' rhetoric shows that such leaders do indeed accentuate the existing in-group prototype and pillory ingroup deviants, as well as demonize appropriate out-groups. Furthermore, use of these rhetorical devices makes the leader appear more effective. Prototypicality management through communication is also central to the way that leaders of social movements politicize members and mobilize them to engage in social action (Reid \& $\mathrm{Ng}, 1999$, 2003). The hurdle for social mobilization is that social protest carries personal risk that inhibits participation (e.g., Klandermans, 1997; Reicher, 2001; Stürmer \& Simon, 2004). Prototypical leaders are effective mobilizers probably because they reduce selfconceptual and normative uncertainty and because followers trust them and are therefore prepared to take risks on their behalf (cf. Tyler, 1997).

High- and low-prototypical leaders need to behave differently to manage their prototypicality (e.g., Platow \& van Knippenberg, 2001). This is because they are differently positioned within the group, such that highly prototypical leaders do 
not need to establish their prototype-based leadership credentials as much as do less prototypical leaders. Highly prototypical leaders' credentials are not called into question, so they do not need to behave in ways that either demonstrate prototypicality or confirm membership. They are trusted by the group to be doing the best for the group-they are central members and therefore what benefits the group must benefit them. They can therefore be innovative and, as long as they are trusted and viewed as high identifiers, they are permitted wide latitude to behave, ironically, in nonprototypical ways. Criticism of the group's norms is tolerated and considered constructive and may lead to normative change (cf. Hornsey and Imani's, 2004, argument that normative critics are more tolerated if they are in-group than outgroup members). Of course, behaviors that are clearly not in the group's best interest will destroy trust and diminish perceived prototypicality and commitment. This is where norm communication, particularly through talk, comes into play-the rhetoric of justification of actions as being in the group's best interest and reflecting the essential identity of the group.

In contrast, low-prototypical leaders' membership credentials are not established and may be called into question. They therefore need to be much more careful to behave overtly in ways that confirm their prototypicality and establish that they are good, loyal, and valid group members. Low-prototypical leaders need to behave highly prototypically - they need to conform, engage in prototypicality talk and behavior, show greater out-group derogation and in-group loyalty, and display greater in-group procedural justice. Criticism of the group's norms is not tolerated, is viewed as destructive, and is very unlikely to lead to normative change.

\section{Marginal members and deviants}

Marginal group members are people who are not very prototypical and therefore they are not particularly liked as group members or trusted as much as more prototypical members. In this respect, they are less able to influence the group than are more central members such as leaders (see Hogg, 2005a). This is not to say that marginal members do not impact group norms-as we discussed above, leaders often use marginal members as reference points to define what the group is not.

Marginal members are often treated as deviants. Marques and his colleagues (e.g., Marques \& Páez, 1994) describe how, in high-salience groups, low-prototypical ingroup members are marginalized and evaluatively downgraded-they are often treated more negatively (as "black sheep") than out-group members holding a similar position. This analysis has been elaborated into the wider subjective group dynamics theory (e.g., Abrams, Marques, Bown, \& Henson, 2000; Marques et al., 2001), which argues that rejection of members who deviate from the group prototype occurs if, and because, such members threaten the integrity of group norms.

Hogg, Fielding, and Darley (2005; Fielding, Hogg, \& Annandale, in press) have suggested that how in-group deviants are treated, and therefore how much subsequent influence they may have over group norms, may be influenced by how they explain their marginal position to the group and whether they are positively or 
negatively deviant-deviance is positive if it makes the group look better than it really is and negative if it makes the group look worse than it really is. Positive deviants who publicly attribute their positive deviance to the actions of the group (modesty), and thus allow the group to own their contribution to the group's positive valence, are favorably treated and embraced by the group as "one of us." Those who publicly take personal responsibility and deny that the group had anything to do with their positive deviance (self-aggrandizement), do not allow the group to own their contribution to the group's positive valence and are marginalized by the group. For negative deviants, the opposite is the case. If they take personal responsibility for their borderline position (self-blame), the group may have some sympathy and attempt to resocialize them. If they do not take personal responsibility (but, rather, blame the group), they will certainly be marginalized.

\section{Marginal groups and minorities}

Deviants do not have to be lone or disparate individuals. Often a group can contain a minority subgroup or some other collective that represents a profound schism in the group's normative structure (e.g., Liebman, Sutton, \& Wuthnow, 1988). These subgroups can be quite effective in influencing the group's norms. Sani and Reicher (1998, 1999) describe how sudden normative change, brought about by the actions of a subgroup or a leadership clique, can produce an acute sense of identity threat and self-conceptual uncertainty, impermanence, and instability. The group is no longer what it used to be-its normative attitudes, values, perceptions, and behaviors have uncompromisingly changed; thus, its identity has changed and members are no longer sure whether they fit the new group.

Under these circumstances, members can try to reestablish the group's original identity through discussion, persuasion, and negotiation, or they can split into a separate subgroup that is in conflict with the rest of the group. A split, or schism, is most likely to occur if members feel the group is intolerant of dissent, unable to embrace diverse views, and inclined toward marginalization of dissenting individuals. A schism effectively transforms one group, a single category, into two separate groups that are engaged in often highly charged intergroup conflict. The split rests on a profound social identity threat that engages a powerful drive to reduce the acute self-conceptual uncertainty that has been aroused. Not surprisingly, schisms can sometimes be very destructive of groups.

Where a schism exists, the subgroup that holds the minority position may paradoxically stand a chance of winning over the rest of the group and reinstating a degree of normative consensus. This might happen if the minority's position was novel, the minority could lay some claim to being a bona fide part of the larger in-group, and the minority adopted a consistent yet flexible style of social influence and persuasion (e.g., Mugny, 1982; Nemeth, 1986). Indeed, although schisms are often highly destructive, the fact that they may sponsor critical thinking, creativity, and innovation may, if properly managed, enhance the larger group (e.g., Nemeth \& Owens, 1996; Nemeth \& Staw, 1989). 


\section{Conclusions and some future directions}

In this article, we have provided an overview of the social identity perspective with reference to group norms. The fundamental insight of this approach is that individuals cognitively represent group norms as category-defining group prototypes that capture meaningful context-dependent similarities within and differences between groups. Social categorization of self and others causes us to assign self and others the attributes of the relevant in- or out-group prototype. In this way, people internalize group norms as prototypes that govern their perception, attitudes, feelings, and behavior-they behave group normatively. Thus, norms are not fixed properties of social groups; they are context dependent and fluid representations that best capture the group in the context of other groups. Because norms map out the contours of groups, people in one group generally share their prototype of their own group and relevant other groups. By definition, group norms are elaborated, maintained, and changed through communication about, and contextualized by, group prototypes. The result of this analysis is that we have a generative mechanism that can be used to explain an array of social psychological and communicative phenomena.

An area that is likely to have much traction for the social identity analysis is the perception of group norms. In addition to research showing conditions that increase correspondence between what people say and do (behavior) and what they actually believe (attitudes), there is, as discussed above, growing evidence that social identity processes influence how people perceive and evaluate media-third-person perceptions and pluralistic ignorance. Future work is likely to extend these ideas to an understanding of health promotion messages. In short, we would expect health promotion to be particularly influential to the extent that a relevant social identity is accessible and salient, and it is promoted by people who are genuinely believed to be highly prototypical in-group members (cf. Lapinski \& Rimal, 2005). Similarly, the media perception work can be extended to such phenomena as the spiral of silence (e.g., Noelle-Neumann, 1984), media uses and gratifications (e.g., Rosengren, Wenner, \& Palmgreen, 1985), media framing effects (Iyengar \& Kinder, 1987), and cultivation (e.g., Gerbner \& Gross, 1976). Indeed, in the perceptual realm, the social identity perspective has the potential to be a truly integrative framework for the communication discipline.

At the same time, many phenomena that have been researched in social psychology by social identity theorists have not yet had sufficient attention paid to their communication dimensions. For example, there is a large literature on group polarization but relatively little research that considers how communication within groups produces a polarized norm or, more generally, how communication actually integrates diverse views within a decision-making group into a group norm. The communicative dimension of hierarchy formation and leadership processes is also underresearched. Prior to this, work on deviance and group schisms has received much attention from social psychologists, but little from communication scholars. 
Yet, there are uniquely communicative dimensions to all these processes: How and when do deviants self-disclose their nonprototypicality? How is language used to engineer and direct group schisms? The confluence of these two areas will provide a fertile ground for much future work.

\section{Acknowledgment}

We would like to acknowledge grant support to Michael Hogg from the Australian Research Council that facilitated our collaboration in writing this article.

\section{References}

Abrams, D., \& Hogg, M. A. (1990). Social identification, self-categorization and social influence. European Review of Social Psychology, 1, 195-228.

Abrams, D., Marques, J. M., Bown, N. J., \& Henson, M. (2000). Pro-norm and anti-norm deviance within in-groups and out-groups. Journal of Personality and Social Psychology, 78, 906-912.

Abrams, D., Wetherell, M. S., Cochrane, S., Hogg, M. A., \& Turner, J. C. (1990). Knowing what to think by knowing who you are: Self-categorization and the nature of norm formation, conformity, and group polarization. British Journal of Social Psychology, 29, 97-119.

Ajzen, I., \& Fishbein, M. (1980). Understanding attitudes and predicting social behavior. Englewood Cliffs, NJ: Prentice Hall.

Arrow, H., \& Burns, K. L. (2004). Self-organizing culture: How norms emerge in small groups. In M. Schaller \& C. S. Crandall (Eds.), The psychological foundations of culture (pp. 171-200). Mahwah, NJ: Erlbaum.

Bendor, J., \& Swistak, P. (2001). The evolution of norms. American Journal of Sociology, 106, 1493-1545.

Bochner, A. P., Ellis, C., \& Tillman-Healy, L. (2000). Relationships as stories: Accounts, storied lives, evocative narratives. In K. Dindia \& S. Duck (Eds.), Communication and personal relationships (pp. 13-29). Chichester, UK: Wiley.

Brewer, M. B., \& Gardner, W. (1996). Who is this 'We'? Levels of collective identity and self representation. Journal of Personality and Social Psychology, 71, 83-93.

Bruner, J. S. (1957). On perceptual readiness. Psychological Review, 64, 123-152.

Burgoon, J. K., Buller, D. B., \& Woodall, W. G. (Eds.). (1996). Nonverbal communication: The unspoken dialogue. New York: McGraw-Hill.

Campbell, D. T. (1958). Common fate, similarity, and other indices of the status of aggregates of persons as social entities. Behavioral Science, 3, 14-25.

Christensen, P. N., Rothgerber, H., Wood, W., \& Matz, D. C. (2004). Social norms and identity relevance: A motivational approach to normative behavior. Personality and Social Psychology Bulletin, 30, 1295-1309.

Cialdini, R. B., Kallgren, C. A., \& Reno, R. R. (1991). A focus theory of normative conduct: A theoretical refinement and re-evaluation of the role of norms in human behavior. In M. P. Zanna (Ed.), Advances in experimental social psychology (Vol. 24, pp. 201-235). San Diego, CA: Academic Press. 
Clark, H. H., \& Brennan, S. E. (1991). Grounding in communication. In L. B. Resnick \& J. Levine (Eds.), Perspectives on socially shared cognition (pp. 127-149). Washington, DC: American Psychological Association.

Côté, P., \& Clément, R. (1994). Language attitudes: An interactive situated approach. Language and Communication, 14, 237-251.

Davison, W. P. (1983). The third-person effect in communication. Public Opinion Quarterly, 47, 1-15.

Deutsch, M., \& Gerard, H. B. (1955). A study of normative and informational social influences upon individual judgment. Journal of Abnormal and Social Psychology, 51, 629-636.

Duck, J. M., Hogg, M. A., \& Terry, D. J. (1999). Social identity and perceptions of media persuasion: Are we always less influenced than others? Journal of Applied Social Psychology, 29, 1879-1899.

Edwards, D. (1997). Discourse and cognition. London: Sage.

Fazio, R. H., \& Olson, M. A. (2003). Attitudes: Foundations, functions, and consequences. In M. A. Hogg \& J. Cooper (Eds.), The Sage handbook of social psychology (pp. 139-160). London: Sage.

Fielding, K. S., Hogg, M. A., \& Annandale, N. (in press). Reactions to positive deviance: Social identity and attribution dimensions. Group Processes and Intergroup Relations.

Fiol, C. M. (2002). Capitalizing on paradox: The role of language in transforming organizational identities. Organization Science, 13, 653-666.

Gardner, M. J., Paulsen, N., Gallois, C., Callan, V. J., \& Monaghan, P. (2001). Communication in organizations: An intergroup perspective. In W. P. Robinson \& H. Giles (Eds.), The new handbook of language and social psychology (pp. 561-584). Chichester, UK: Wiley.

Gerbner, G., \& Gross, L. (1976). Living with television: The violence profile. Journal of Communication, 26, 173-199.

Giles, H., \& Coupland, N. (1991). Language: Context and consequences. Milton Keynes, UK: Open University Press.

Giles, H., \& Johnson, P. (1981). The role of language in ethnic group relations. In J. C. Turner \& H. Giles (Eds.), Intergroup behavior (pp. 199-243). Oxford, UK: Blackwell.

Giles, H., \& Johnson, P. (1987). Ethnolinguistic identity theory: A social psychological approach to language maintenance. International Journal of the Sociology of Language, 68, 66-99.

Hamilton, D. L., \& Sherman, S. J. (1996). Perceiving persons and groups. Psychological Review, 103, 336-355.

Haslam, S. A., Oakes, P. J., McGarty, C., Turner, J. C., \& Onorato, S. (1995). Contextual changes in the prototypicality of extreme and moderate outgroup members. European Journal of Social Psychology, 25, 509-530.

Higgins, E. T. (1992). Achieving "shared reality" in the communication game: A social action that creates meaning. Journal of Language and Social Psychology, 11, 107-131.

Hogg, M. A. (2000). Subjective uncertainty reduction through self-categorization: A motivational theory of social identity processes. European Review of Social Psychology, 11, 223-255.

Hogg, M. A. (2001). A social identity theory of leadership. Personality and Social Psychology Review, 5, 184-200. 
Hogg, M. A. (2003). Social identity. In M. R. Leary \& J. P. Tangney (Eds.), Handbook of self and identity (pp. 462-479). New York: Guilford.

Hogg, M. A. (2005a). All animals are equal but some animals are more equal than others: Social identity and marginal membership. In K. D. Williams, J. P. Forgas, \& W. von Hippel (Eds.), The social outcast: Ostracism, social exclusion, rejection and bullying (pp. 243-261). New York: Psychology Press.

Hogg, M. A. (2005b). The social identity perspective. In S. A. Wheelan (Ed.), The handbook of group research and practice (pp. 133-157). Thousand Oaks, CA: Sage.

Hogg, M. A. (2006). Social identity theory. In P. J. Burke (Ed.), Contemporary social psychological theories (pp. 111-136). Palo Alto, CA: Stanford University Press.

Hogg, M. A., \& Abrams, D. (1988). Social identifications: A social psychology of intergroup relations and group processes. London: Routledge.

Hogg, M. A., Fielding, K. S., \& Darley, J. (2005). Fringe dwellers: Processes of deviance and marginalization in groups. In D. Abrams, M. A. Hogg, \& J. M. Marques (Eds.), The social psychology of inclusion and exclusion (pp. 191-210). New York: Psychology Press.

Hogg, M. A., \& Tindale, R. S. (2005). Social identity, influence, and communication in small groups. In J. Harwood \& H. Giles (Eds.), Intergroup communication: Multiple perspectives (pp. 141-164). New York: Peter Lang.

Hogg, M. A., \& Turner, J. C. (1987). Social identity and conformity: A theory of referent informational influence. In W. Doise \& S. Moscovici (Eds.), Current issues in European social psychology (Vol. 2, pp. 139-182). Cambridge, UK: Cambridge University Press.

Hogg, M. A., \& van Knippenberg, D. (2003). Social identity and leadership processes in groups. In M. P. Zanna (Ed.), Advances in experimental social psychology (Vol. 35, pp. 1-52). San Diego, CA: Academic Press.

Hornsey, M. J., \& Imani, A. (2004). Criticising groups from the inside and the outside: An identity perspective on the intergroup sensitivity effect. Personality and Social Psychology Bulletin, 30, 365-383.

Isenberg, D. J. (1986). Group polarization: A critical review. Journal of Personality and Social Psychology, 50, 1141-1151.

Iyengar, S., \& Kinder, D. R. (1987). News that matters. Chicago: Chicago University Press.

Kashima, Y. (2000). Maintaining cultural stereotypes in the serial reproduction of narratives. Personality and Social Psychology Bulletin, 26, 594-604.

Kincaid, D. L. (2004). From innovation to social norm: Bounded normative influence. Journal of Health Communication, 9, 37-57.

Klandermans, B. (1997). The social psychology of protest. Oxford, UK: Blackwell.

Lapinski, M. K., \& Rimal, R. N. (2005). An explication of social norms. Communication Theory, 15, 127-147.

Larson, J. R., Jr., Foster-Fishman, P. G., \& Keys, C. B. (1994). Discussion of shared and unshared information in decision-making groups. Journal of Personality and Social Psychology, 67, 446-461.

Levine, J. M., \& Moreland, R. L. (1994). Group socialization: Theory and research. European Review of Social Psychology, 5, 305-336.

Liebman, R. C., Sutton, J. R., \& Wuthnow, R. (1988). Exploring the social sources of denominationalism: Schisms in American Protestant denominations, 1890-1980. American Sociological Review, 53, 343-352. 
Maass, A. (1999). Linguistic intergroup bias: Stereotype perpetuation through language. Advances in Experimental Social Psychology, 31, 79-121.

Mackie, D. M. (1986). Social identification effects in group polarization. Journal of Personality and Social Psychology, 50, 720-728.

Mackie, D. M., \& Cooper, J. (1984). Attitude polarization: The effects of group membership. Journal of Personality and Social Psychology, 46, 575-585.

Mackie, D. M., Hamilton, D. L., Susskind, J., \& Rosselli, F. (1996). Social psychological foundations of stereotype formation. In C. N. Macrae, C. Stangor, \& M. Hewstone (Eds.), Stereotypes and stereotyping (pp. 41-78). New York: Guilford.

MacNeil, M., \& Sherif, M. (1976). Norm change over subject generations as a function of arbitrariness of prescribed norms. Journal of Personality and Social Psychology, 34, 762-773.

Markus, H. R., \& Kitayama, S. (1991). Culture and the self: Implications for cognition, emotion, and motivation. Psychological Review, 98, 224-253.

Marques, J. M., Abrams, D., \& Serôdio, R. (2001). Being better by being right: Subjective group dynamics and derogation of in-group deviants when generic norms are undermined. Journal of Personality and Social Psychology, 81, 436-447.

Marques, J. M., \& Páez, D. (1994). The 'black sheep effect': Social categorization, rejection of ingroup deviates and perception of group variability. European Review of Social Psychology, 5, 37-68.

Moscovici, S. (1976). Social influence and social change. London: Academic Press.

Moscovici, S., \& Zavalloni, M. (1969). The group as a polarizer of attitudes. Journal of Personality and Social Psychology, 12, 125-135.

Mugny, G. (1982). The power of minorities. London: Academic Press.

Nemeth, C. (1986). Differential contributions of majority and minority influence. Psychological Review, 93, 23-32.

Nemeth, C., \& Owens, P. (1996). Making work groups more effective: The value of minority dissent. In M. A. West (Ed.), The handbook of workgroup psychology (pp. 125-141). Chichester, UK: Wiley.

Nemeth, C., \& Staw, B. M. (1989). The tradeoffs of social control and innovation in groups and organizations. In L. Berkowitz (Ed.), Advances in experimental social psychology (Vol. 22, pp. 175-210). San Diego, CA: Academic Press.

Noelle-Neumann, E. (1984). The spiral of silence: Public opinion and our social skin. Chicago: University of Chicago Press.

Noels, K. A., Giles, H., \& Le Poire, B. (2003). Language and communication processes. In M. A. Hogg \& J. Cooper (Eds.), The Sage handbook of social psychology (pp. 232-257). London: Sage.

Oakes, P. J. (1987). The salience of social categories. In J. C. Turner, M. A. Hogg, P. J. Oakes, S. D. Reicher, \& M. S. Wetherell (Eds.), Rediscovering the social group: A self-categorization theory (pp. 117-141). Oxford, UK: Blackwell.

Oakes, P. J., Haslam, S. A., \& Turner, J. C. (1993). Stereotyping and social reality. Oxford, UK: Blackwell.

Oyserman, D., Coon, H. M., \& Kemmelmeier, M. (2002). Rethinking individualism and collectivism: Evaluation of theoretical assumptions and meta-analyses. Psychological Bulletin, 128, 3-72. 
Perloff, R. M. (1993). Third-person research 1983-1992: A review and synthesis. International Journal of Public Opinion Research, 5, 167-184.

Platow, M. J., \& van Knippenberg, D. (2001). A social identity analysis of leadership endorsement: The effects of leader ingroup prototypicality and distributive intergroup fairness. Personality and Social Psychology Bulletin, 27, 1508-1519.

Postmes, T., Spears, R., \& Cihangir, S. (2001). Quality of decision-making and group norms. Journal of Personality and Social Psychology, 80, 918-930.

Prentice, D. A., \& Miller, D. T. (1993). Pluralistic ignorance and alcohol use on campus: Some consequences of misperceiving the social norm. Journal of Personality and Social Psychology, 64, 243-256.

Prentice, D. A., \& Miller, D. T. (1996). Pluralistic ignorance and the perpetuation of social norms by unwitting actors. In M. P. Zanna (Ed.), Advances in experimental social psychology (Vol. 28, pp. 161-209). New York: Academic Press.

Reicher, S. D. (1984). The St Pauls' riot: An explanation of the limits of crowd action in terms of a social identity model. European Journal of Social Psychology, 14, 1-21.

Reicher, S. D. (2001). The psychology of crowd dynamics. In M. A. Hogg \& R. S. Tindale (Eds.), Blackwell handbook of social psychology: Group processes (pp. 182-208). Oxford, UK: Blackwell.

Reicher, S. D., \& Hopkins, N. (1996). Self-category constructions in political rhetoric: An analysis of Thatcher's and Kinnock's speeches concerning the British miners' strike (1984-5). European Journal of Social Psychology, 26, 353-371.

Reicher, S. D., \& Hopkins, N. (2001). Self and nation. London: Sage.

Reid, S. A., Byrne, S., Brundidge, J., Shoham, M., \& Marlow, M. (2005). Predicting first- and third-person perceptions for pornography: Further evidence for a self-categorization explanation. Manuscript submitted for publication.

Reid, S. A., Cropley, C., \& Hogg, M. A. (2005). A self-categorization explanation of pluralistic ignorance. Top three paper, presented at the International Communication Association, New York.

Reid, S. A., Giles, H., \& Harwood, J. (2005). A prospectus for the study of communication and intergroup relations. In J. Harwood \& H. Giles (Eds.), Intergroup communication: Multiple perspectives (pp. 241-263). New York: Peter Lang.

Reid, S. A., \& Hogg, M. A. (2005). A self-categorization explanation of the third-person effect. Human Communication Research, 31, 129-161.

Reid, S. A., \& Ng, S. H. (1999). Language, power and intergroup relations. Journal of Social Issues, 55, 119-139.

Reid, S. A., \& Ng, S. H. (2000). Conversation as a resource for influence: Evidence for prototypical arguments and social identification processes. European Journal of Social Psychology, 30, 83-100.

Reid, S. A., \& Ng, S. H. (2003). Identity, power, and strategic social categorizations: Theorizing the language of leadership. In D. van Knippenberg \& M. A. Hogg (Eds.), Leadership and power: Identity processes in groups and organizations (pp. 210-223). London: Sage.

Rimal, R. N., \& Real, K. (2003). Understanding the influence of perceived norms on behaviors. Communication Theory, 13, 184-203.

Rosengren, K. E., Wenner, L. A., \& Palmgreen, P. (Eds.). (1985). Media gratifications research: Current perspectives. Beverly Hills, CA: Sage. 
Sani, F., \& Reicher, S. D. (1998). When consensus fails: An analysis of the schism within the Italian Communist Party (1991). European Journal of Social Psychology, 28, 623-645.

Sani, F., \& Reicher, S. D. (1999). Identity, argument and schisms: Two longitudinal studies of the split in the Church of England over the ordination of women to the priesthood. Group Processes and Intergroup Relations, 2, 279-300.

Scherer, K. R., \& Giles, H. (Eds.). (1979). Social markers in speech. Cambridge, UK: Cambridge University Press.

Sherif, M. (1935). A study of some social factors in perception. Archives of Psychology, 27, $1-60$.

Sherif, M. (1936). The psychology of social norms. New York: Harper.

Stasser, G., Stewart, D. D., \& Wittenbaum, G. M. (1995). Expert roles and information exchange during discussion: The importance of knowing who knows what. Journal of Experimental Social Psychology, 31, 244-265.

Stasser, G., \& Titus, W. (1985). Pooling of unshared information in group decision-making: Biased information sampling during discussion. Journal of Personality and Social Psychology, 48, 1467-1478.

Stasser, G., \& Titus, W. (1987). Effects of information load and percentage of shared information on the dissemination of unshared information during group discussion. Journal of Personality and Social Psychology, 53, 81-93.

Stürmer, S., \& Simon, B. (2004). Collective action: Towards a dual-pathway model. European Review of Social Psychology, 15, 59-99.

Tajfel, H. (1959). Quantitative judgement in social perception. British Journal of Psychology, $50,16-29$.

Tajfel, H. (1969). Cognitive aspects of prejudice. Journal of Social Issues, 25, 79-97.

Tajfel, H. (1972). Social categorization. English manuscript of "La catégorisation sociale." In S. Moscovici (Ed.), Introduction à la psychologie sociale (Vol. 1, pp. 272-302). Paris: Larousse.

Tajfel, H. (1981). Social stereotypes and social groups. In J. C. Turner \& H. Giles (Eds.), Intergroup behaviour (pp. 144-167). Oxford, UK: Blackwell.

Tajfel, H., Billig, M., Bundy, R. P., \& Flament, C. (1971). Social categorization and intergroup behaviour. European Journal of Social Psychology, 1, 149-177.

Tajfel, H., \& Turner, J. C. (1979). An integrative theory of intergroup conflict. In W. G. Austin \& S. Worchel (Eds.), The social psychology of intergroup relations (pp. 33-47). Monterey, CA: Brooks/Cole.

Terry, D. J., \& Hogg, M. A. (1996). Group norms and the attitude-behavior relationship: A role for group identification. Personality and Social Psychology Bulletin, 22, 776-793.

Terry, D. J., \& Hogg, M. A. (2001). Attitudes, behavior, and social context: The role of norms and group membership in social influence processes. In J. P. Forgas \& K. D. Williams (Eds.), Social influence: Direct and indirect processes (pp. 253-270). Philadelphia: Psychology Press.

Thompson, L., \& Fine, G. A. (1999). Socially shared cognition, affect, and behavior: A review and integration. Personality and Social Psychology Review, 3, 278-302.

Tuckman, B. W. (1965). Developmental sequence in small groups. Psychological Bulletin, 63, 384-399. 
Turner, J. C. (1982). Towards a cognitive redefinition of the social group. In H. Tajfel (Ed.), Social identity and intergroup relations (pp. 15-40). Cambridge, UK: Cambridge University Press.

Turner, J. C. (1991). Social influence. Milton Keynes, UK: Open University Press.

Turner, J. C., Hogg, M. A., Oakes, P. J., Reicher, S. D., \& Wetherell, M. S. (1987). Rediscovering the social group: A self-categorization theory. Oxford, UK: Blackwell.

Turner, J. C., \& Oakes, P. J. (1986). The significance of the social identity concept for social psychology with reference to individualism, interactionism and social influence. British Journal of Social Psychology, 25, 237-252.

Turner, J. C., \& Oakes, P. J. (1989). Self-categorization and social influence. In P. B. Paulus (Ed.), The psychology of group influence (2nd ed., pp. 233-275). Hillsdale, NJ: Erlbaum.

Turner, J. C., Wetherell, M. S., \& Hogg, M. A. (1989). Referent informational influence and group polarization. British Journal of Social Psychology, 28, 135-147.

Tyler, T. R. (1997). The psychology of legitimacy: A relational perspective on voluntary deference to authorities. Personality and Social Psychology Review, 1, 323-345.

van Knippenberg, D., \& Hogg, M. A. (2003). A social identity model of leadership in organizations. In R. M. Kramer \& B. M. Staw (Eds.), Research in organizational behavior (Vol. 25, pp. 243-295). Greenwich, CT: JAI Press.

van Knippenberg, D., van Knippenberg, B., De Cremer, D., \& Hogg, M. A. (2004). Leadership, self, and identity: A review and research agenda. The Leadership Quarterly, 15, 825-856.

Wigboldus, D. H., Semin, G., \& Spears, R. (2000). How do we communicate stereotypes? Linguistic bases and inferential consequences. Journal of Personality and Social Psychology, 78, 5-18.

Wittenbaum, G. M., Hubbell, A., \& Zuckerman, C. (1999). Mutual enhancement: Toward an understanding of the collective preference for shared information. Journal of Personality and Social Psychology, 77, 967-978. 